\title{
Characterization of efficient xylanases from industrial-scale pulp and paper wastewater treatment microbiota
}

Jia Wang ${ }^{1}$, Jiawei Liang ${ }^{2}$, Yonghong $\mathrm{Li}^{1^{*}}$, Lingmin Tian ${ }^{3^{*}}$ and Yongjun $\mathrm{Wei}^{\mathrm{i}^{*}}$

\begin{abstract}
Xylanases are widely used enzymes in the food, textile, and paper industries. Most efficient xylanases have been identified from lignocellulose-degrading microbiota, such as the microbiota of the cow rumen and the termite hindgut. Xylanase genes from efficient pulp and paper wastewater treatment (PPWT) microbiota have been previously recovered by metagenomics, assigning most of the xylanase genes to the GH10 family. In this study, a total of $40 \mathrm{GH} 10$ family xylanase genes derived from a certain PPWT microbiota were cloned and expressed in Escherichia coli BL21 (DE3). Among these xylanase genes, 14 showed xylanase activity on beechwood substrate. Two of these, PW-xyl9 and PW-xyl37, showed high activities, and were purified to evaluate their xylanase properties. Values of optimal pH and temperature for $\mathrm{PW}$-xyl9 were $\mathrm{pH} 7$ and $60{ }^{\circ} \mathrm{C}$, respectively, while those for $\mathrm{PW}$-xyl37 were $\mathrm{pH} 7$ and $55^{\circ} \mathrm{C}$, respectively; their specific xylanase activities under optimal conditions were $470.1 \mathrm{U} / \mathrm{mg}$ protein and $113.7 \mathrm{U} / \mathrm{mg}$ protein, respectively. Furthermore, the $K m$ values of PW-xyl9 and PW-xyl37 were determined as 8.02 and $18.8 \mathrm{~g} / \mathrm{L}$, respectively. The characterization of these two xylanases paves the way for potential application in future pulp and paper production and other industries, indicating that PPWT microbiota has been an undiscovered reservoir of efficient lignocellulase genes. This study demonstrates that a metagenomic approach has the potential to screen efficient xylanases of uncultured microorganisms from lignocellulose-degrading microbiota. In a similar way, other efficient lignocellulase genes might be identified from PPWT treatment microbiota in the future.
\end{abstract}

Keywords: Metagenome, Xylanase, GH10 family, Xylan, Pulp and paper wastewater

\section{Keypoints}

- Xylanases sourced from a certain pulp and paper wastewater treatment microbiota were cloned and characterized

- Two xylanases had high performance under wide $\mathrm{pH}$ and temperature ranges

\footnotetext{
*Correspondence: Iyh224@163.com; tianlinmin@163.com; yongjunwei@zzu. edu.cn

${ }^{1}$ Key Laboratory of Advanced Drug Preparation Technologies, Ministry of Education, School of Pharmaceutical Sciences, Zhengzhou University, Zhengzhou, People's Republic of China

${ }^{3}$ Department of Food Science and Engineering, Jinan University, Guangzhou 510632, People's Republic of China

Full list of author information is available at the end of the article
}

- The potential structures of active sites of the two xylanases were identified through bioinformatics analyses

\section{Introduction}

Xylan, a major component of hemicellulose in plant cells, is among the most abundant natural sources of renewable biomass (Scheller and Ulvskov 2010; Walia et al. 2017). It consists of xylose units connected through $\beta-1,4$-glycosidic bonds and side chains composed of $\alpha$-Dglucuronide, arabinose, galactose, acetate, methyl glucuronic acid and other simple sugars (Houfani et al. 2020). The microbial degradation of xylan requires the synergy of a variety of enzymes-with xylanase as the most essential among them-which can hydrolyze $\beta$-1,4-glycosidic 
bonds to produce xylose or xylose oligosaccharides (Shallom and Shoham 2003). Xylanases are widely used in the paper manufacturing, textile, biofuel, food and other industries, as they can increase the efficiency of lignocellulose usage and reduce environmental pollution (Juturu and Wu 2012; Kumar et al. 2018). Previously, fungal xylanases were mainly used for the degradation of xylan from plant biomass during biofuel manufacture and other industrial applications (Torres and Dela Cruz 2013; Walia et al. 2017). Due to the diversity of naturally occurring efficient lignocellulose degradation systems, there is a possibility to recover novel types of xylanase from these for the efficient enzymatic degradation of xylan (Mhiri et al. 2020).

With the development of microbiome profiling and other high-throughput sequencing technologies, xylanases were identified in typical efficient lignocellulose degradation microbiota, such as biogas digesters, the termite hindgut, the cow rumen, and the camel gut (Gharechahi and Salekdeh 2018; Liu et al. 2019; Stewart et al. 2018; Wei et al. 2015). At least 386 different xylanase genes were screened from a single biogas digester, with xylanase activities detected by the expression of the recovered xylanase genes in Escherichia coli (Wei et al. 2015; Yan et al. 2013). The termite hindgut is an efficient microbial niche for lignocellulose degradation, from where certain xylanases have been identified (Liu et al. 2011, 2019). Some of these xylanases show high xylanase activity, which partly explains the reason for the high lignocellulose-degrading efficiency of the termite (Han et al. 2013; Qian et al. 2015). A total of 913 microbial genomes and 69,000 genes related to carbohydrate metabolism were identified through the assembly of cow rumen metagenomic sequences, characterizing the cow rumen as a reservoir of xylanase genes (Stewart et al. 2018). The artificial rumen system is highly efficient in degrading lignocellulose for methane production (Xing et al. 2020), harboring diverse functional xylanases (Loaces et al. 2016). Moreover, many efficient xylanase genes have been isolated from camel and kangaroo gut microbiota (Gharechahi and Salekdeh 2018; Wirth et al. 2018); some of them showed alkali-thermostable characteristics, which makes them useful in the enhancement of recalcitrant lignocellulose biomass degradation (Ariaeenejad et al. 2019; Ghadikolaei et al. 2019).

Diverse xylanases are present in most biogas digesters inoculated with lignocellulose, thus they have the ability to degrade lignocellulose efficiently (Liang et al. 2021; Sawatdeenarunat et al. 2015; Wei et al. 2015). Paper and pulp manufacture wastewater contains high levels of lignocellulose waste, and the microbiota used to treat such wastewater harbors a diversity of lignocellulose genes. In our previous study, over 93,000 genes predicted to be associated with carbohydrate metabolism were identified in the anaerobic and aerobic microbiota used for pulp and paper wastewater treatment (PPWT) (Liang et al. 2021). These xylanase genes belonged to more than 16 different glycoside hydrolase $(\mathrm{GH})$ families in the CAZy database, with most enzymes of GH10 and GH11 families showing xylanase activity (Lombard et al. 2014). Most xylanase genes were assigned to the GH10 family among these genes, and more than 100 GH10 family genes or gene fragments were identified in the PPWT microbiota (Liang et al. 2021). Meanwhile, no GH11 family genes were recovered from the anaerobic microbiota, and only eleven GH11 family gene fragments were identified in the aerobic microbiota of the PPWT plant (Liang et al. 2021).

Xylanases of the GH10 family, which normally have high molecular weight and a $(\beta / \alpha)_{8} 8$-barrel folding structure, hydrolyze xylan through a reservation-type catalytic mechanism (Kim et al. 2018; Zhang et al. 2016). Crystal structure and dynamics analysis have revealed that these xylanases have four to five active binding sites, and often contain carbohydrate-binding modules (CBM) connected to their catalytic structural domain (Jia and Han 2019; Wu et al. 2020). These CBM molecules help to improve the specific binding of xylanases to lignocellulose substrate, leading to enhanced xylan hydrolysis ability (Bhardwaj et al. 2012; Collins et al. 2005). The Xyn10J xylanase obtained from the metagenomic library of one compost microbiota can improve the saccharification of lignocellulose in biomass, and is useful for the production of fermented sugars (Jeong et al. 2012). The GH10 xylanases of efficient lignocellulose-degrading PPWT microbiota might harbor high xylanase ability, and are robust to extreme xylanase reaction environments (Liang et al. 2021).

In the current study, we attempt to characterize GH10 family xylanase genes from the efficient microbiota of a specific PPWT facility (Liang et al. 2021). Cloned fulllength GH10 family genes were expressed in E. coli, the activities of two expressed GH10 family xylanases were characterized, and their xylanase properties were described in details.

\section{Materials and methods}

\section{Strains, plasmid, and reagents}

E. coli TOP10 and BL21 cell (DE3) strains were purchased from Tolo Biotechnology (Anhui, China). The beechwood as xylanase substrate was sourced from Megazyme Co. Ltd (www.megazyme.com). The 3,5-dinitrosalicylic acid (DNS) and other chemical reagents were obtained from 
China National Pharmaceutical Group Co., Ltd. (Haidian District, Beijing, China) (Hu et al. 2008).

\section{DNA analysis, screening and plasmid construction}

In a previous study, a diverse array of CAZy genes and a total of $162 \mathrm{GH} 10$ family genes were recovered from the microbiota of a particular PPWT plant by metagenomic assembly (Liang et al. 2021). In our study, the GH10 family genes that were predicted to be full-length and showed more than $25 \%$ identity with known xylanase genes in the GenBank database were selected for further cloning. Finally, a total of 40 xylanase genes were ultimately verified by Sanger sequencing, and were named as $P W-X y l 1$ to $P W-X y l 40$ (Table 1 ). These genes were aligned with certain high activity xylanase genes downloaded from the enzyme repository of the ExPaSy database at https://enzyme.expasy.org/. The phylogenetic tree of xylanase genes was constructed with MEGA 7 using the Test UPGMA tree method (Kumar et al. 2016), and was further polished with iTOL (Letunic and Bork 2019).

The primers were designed and used for the cloning of xylanase genes in the pET28 expression plasmid (Additional file 1: Table S1). The DNA extracted from the microbiota of the targeted PPWT plant was used as template, and Phanta Max Super-Fidelity DNA polymerase (NO. P505, Nanjing, China) was used for gene amplification. All 40 GH10 family genes were cloned and verified by Sanger sequencing; their accession numbers are MW124392-MW124431 in the GenBank database.

The genes were separately ligated into pET28a $(+)$ using the homologous recombinant enzyme (Novogene, Beijing, China) according to the manufacturer's instructions. Subsequently, the recombinant mixtures were transformed into the E. coli TOP10 strain. Following verification, the recombinant plasmids obtained from the TOP10 strain were further transformed into the $E$. coli BL21 strain.

\section{Expression and detection of recombinant proteins}

The E. coli BL21 strains including the recombinant plasmids were inoculated into $100 \mathrm{~mL} \mathrm{LB}$ medium containing kanamycin $(50 \mu \mathrm{g} / \mathrm{mL})$ in a $500 \mathrm{~mL}$ shake flask, and incubated at $37{ }^{\circ} \mathrm{C}$. Once each $E$. coli BL21 culture harboring a xylanase gene had grown to reach an OD600 value of $0.8,200 \mathrm{mM}$ IPTG was added to the culture in order to induce xylanase expression. After cultivation for further $16 \mathrm{~h}$ at $20{ }^{\circ} \mathrm{C}$, cells were harvested by centrifugation at $12,000 \mathrm{rpm}$ for $5 \mathrm{~min}$. Harvested cells were washed with phosphate buffered saline (PBS) buffer (pH 7.4), and then disrupted with supersonic waves (Xiaomei, Kunshan, China) on ice for $15 \mathrm{~min}$ using the method of $5 \mathrm{~s}$ pulses and $10 \mathrm{~s}$ intervals (Yan et al. 2013). Finally, cells were centrifuged at 12,000 rpm for $10 \mathrm{~min}$, and the supernatant was used for the xylanase activity assay.

The DNS method was applied to determine xylanase activity based on the release of reducing sugar from the mixture of xylanase and beechwood substrate (Wei et al. 2015). A cell supernatant of $25 \mu \mathrm{L}$ volume was mixed with $25 \mu \mathrm{L}$ xylan $(4 \mathrm{mg} / \mathrm{mL})$, and the mixture was left to react for an hour in total, including $20^{\circ} \mathrm{C}$ for $20 \mathrm{~min}, 40{ }^{\circ} \mathrm{C}$ for $20 \mathrm{~min}$, and $60{ }^{\circ} \mathrm{C}$ for further $20 \mathrm{~min}$. Subsequently, $50 \mu \mathrm{L}$ DNS reagent was added to tubes to stop the enzymatic reaction, and the mixtures were further incubated in a $95{ }^{\circ} \mathrm{C}$ water bath for $5 \mathrm{~min}$. Finally, the crude activity of xylanase could be determined (Yan et al. 2013).

\section{Recombinant protein expression and purification}

Two BL21 strains with xylanase genes of $P W-x y l 9$ or $P W-$ $x y l 37$ were selected for further characterization. The corresponding strains were incubated overnight in a shaker at $37{ }^{\circ} \mathrm{C}$ and $200 \mathrm{rpm} ; 4 \mathrm{~mL}$ of the overnight culture was then inoculated to $200 \mathrm{~mL}$ fresh $\mathrm{LB}$ medium in a $1 \mathrm{~L}$ shake flask for further culturing. Once the OD600 value of the two strains had reached 0.8, $200 \mathrm{mM}$ IPTG was added, and the culture was cultivated at $20{ }^{\circ} \mathrm{C}$ for an additional $16 \mathrm{~h}$. Cells were harvested and washed $3 \times$ with PBS buffer, and were suspended in $20 \mathrm{~mL}$ PBS buffer with $1 \mathrm{mM}$ phenylmethylsulfonyl fluoride (PMSF) which was protease inhibitor. The cells were disrupted by sonication for a total length of $15 \mathrm{~min}$ (Xiaomei, Kunshan, China), with setting parameters of $150 \mathrm{~W}, 3 \mathrm{~s}$ on, and $5 \mathrm{~s}$ off. The cell suspensions were centrifuged at $12,000 \mathrm{rpm}$ at $4{ }^{\circ} \mathrm{C}$ for $20 \mathrm{~min}$, and the supernatant was collected as crude enzyme. Magnetic beads (PuriMag, Xiamen, China) were used for protein purification, and the purified proteins obtained were concentrated in $10 \mathrm{kDa}$ ultrafiltration tubes (Merck, Millipore, USA). The purity of proteins was determined by sodium dodecyl sulfate-polyacrylamide gel electrophoresis (SDS-PAGE), and their concentrations were measured with the Bradford method (Sangon Biotech, Shanghai, China).

\section{Enzymatic assay}

Enzyme activity was measured in $1 \%$ beechwood xylan dissolved in PBS Buffer with a $\mathrm{pH}$ value of 7.4. The enzyme reaction mixtures comprised of $50 \mu \mathrm{L} 2 \%$ xylan and $50 \mu \mathrm{L}$ enzyme solution. Mixtures were left to react at $50{ }^{\circ} \mathrm{C}$ for $10 \mathrm{~min}$, and the reaction was terminated with the addition of $100 \mu \mathrm{L}$ DNS reagent solution. The resulting reaction mixtures of $200 \mu \mathrm{L}$ volume were further incubated at $95{ }^{\circ} \mathrm{C}$ for $5 \mathrm{~min}$. The final solutions were cooled on ice, and $120 \mu \mathrm{L}$ of each reaction mixture was used for absorbance measurement at $540 \mathrm{~nm}$ (Teixeira et al. 2012). The specific enzyme activity (U/mg protein) 
Table 1 The 40 cloned xylanase genes and their closest gene counterparts in the GenBank database

\begin{tabular}{|c|c|c|c|c|}
\hline Name & $\mathrm{AA}^{\mathrm{a}}$ & Closest genes and their accession numbers & Identity (\%) & $\mathbf{S}^{\mathbf{b}}$ \\
\hline$P W-x y / 1$ & 333 & TPA: 1,4- $\beta$-xylanase [Cyanobacteria bacterium] (UBA11371) (HAZ45611.1) & 55.66 & \\
\hline$P W-x y / 2$ & 360 & Endo-1,4- $\beta$-xylanase [uncultured bacterium Contig15] (AHF23866.1) & 77.87 & \\
\hline$P W-x y / 3$ & 368 & Endo-1,4- $\beta$-xylanase [Hallella seregens] (WP_052323291.1) & 75.68 & \\
\hline$P W-x y / 4$ & 369 & Endo-1,4- $\beta$-xylanase [Candidatus Atribacteria bacterium] (TFG90307.1) & 73.49 & $\checkmark$ \\
\hline$P W-x y / 5$ & 370 & Endo-1,4- $\beta$-xylanase [Ignavibacteriae bacterium] (RPI05742.1) & 51.52 & $\checkmark$ \\
\hline$P W-x y l 6$ & 372 & Endo-1,4- $\beta$-xylanase [Ignavibacteriae bacterium] (RPI05742.1) & 53.68 & \\
\hline$P W-x y l 7$ & 374 & Endo-1,4- $\beta$-xylanase [Rufibacter sp. R-22-1c-1] (WP_123126834.1) & 63.71 & $\checkmark$ \\
\hline$P W-x y / 8$ & 374 & Endo-1,4- $\beta$-xylanase [Paludibacterjiangxiensis] (WP_068704526.1) & 81.01 & $\checkmark$ \\
\hline$P W-x y / 9$ & 377 & Endo-1,4- $\beta$-xylanase [Bacteroidales bacterium] (NL21332.1) & 89.30 & $\checkmark$ \\
\hline$P W-x y / 10$ & 383 & Endo-1,4- $\beta$-xylanase [Alkalilimnicola ehrlichii] (WP_116303324.1) & 56.84 & $\checkmark$ \\
\hline$P W-x y / 11$ & 383 & Endo-1,4- $\beta$-xylanase [Runella sp. YX9] (WP_114464289.1) & 69.94 & $\checkmark$ \\
\hline$P W-x y / 12$ & 383 & Endo-1,4- $\beta$-xylanase [Runella sp. YX9] (WP_114464289.1) & 70.45 & $\checkmark$ \\
\hline$P W-x y / 13$ & 390 & 1,4- $\beta$-xylanase [Flavobacteriia bacterium] (RUA15923.1) & 58.79 & $\checkmark$ \\
\hline$P W-x y / 14$ & 391 & Endo-1,4- $\beta$-xylanase [Confluentibacter lentus] (WP_100611294.1) & 71.90 & $\checkmark$ \\
\hline$P W-x y / 15$ & 396 & TPA: 1,4- $\beta$-xylanase [Planctomycetes bacterium] (HAK94543.1) & 77.31 & $\checkmark$ \\
\hline$P W-x y / 16$ & 403 & 1,4- $\beta$-xylanase [Butyrivibrio sp. NC2007] (WP_022770809.1) & 52.21 & \\
\hline$P W-x y / 17$ & 413 & TPA: 1,4- $\beta$-xylanase [Cyanobacteria bacterium UBA11371] (HAZ45611.1) & 48.50 & $\checkmark$ \\
\hline$P W-x y / 18$ & 415 & Endo-1,4- $\beta$-xylanase, GH35 family [Bacteroidales bacterium 6E] (GAP68157.1) & 58.29 & \\
\hline$P W-x y / 19$ & 420 & Endo-1,4- $\beta$-xylanase [Planctomycetaceae bacterium] (RPJ36220.1) & 74.31 & \\
\hline$P W-x y \mid 20$ & 422 & 1,4- $\beta$-xylanase [Microbispora sp. GKU 823] (WP_079313614.1) & 63.19 & $\checkmark$ \\
\hline$P W-x y / 21$ & 424 & Endo-1,4- $\beta$-xylanase [Bacteroidales bacterium 6E] (GAP68157.1) & 64.34 & \\
\hline$P W-x y 122$ & 425 & Endo-1,4- $\beta$-xylanase [Bacteroidales bacterium 6E] (GAP68157.1) & 64.92 & \\
\hline$P W-x y \mid 23$ & 426 & Endo-1,4- $\beta$-xylanase [Bacteroidales bacterium 6E] (GAP68157.1) & 60.21 & \\
\hline$P W-x y / 24$ & 451 & Endo-1,4- $\beta$-xylanase Z [Tannerella forsythia] (SCQ20945.1) & 34.57 & \\
\hline$P W-x y / 25$ & 452 & 1,4- $\beta$-xylanase [Thermogutta terrifontis] (WP_095416323.1) & 55.15 & \\
\hline$P W-x y \mid 26$ & 460 & 1,4- $\beta$-xylanase [Planctomycetes bacterium B3_Pla] (TKJ36372.1) & 60.67 & \\
\hline$P W-x y 127$ & 475 & ß-1,4-xylanase [Mesotoga infera] (KUK68222.1) & 76.09 & \\
\hline$P W-x y \mid 28$ & 476 & Endo-1,4- $\beta$-xylanase [Cyanothece sp. PCC 7822] (WP_013324907.1) & 27.16 & \\
\hline$P W-x y 129$ & 492 & 1,4- $\beta$-xylanase [Aphanothece sacrum] (WP_124970705.1) & 27.23 & \\
\hline$P W-x y / 30$ & 495 & 1,4- $\beta$-xylanase [Chthonomonas calidirosea T49] (CCW34445.1) & 43.40 & \\
\hline$P W-x y / 31$ & 496 & Endo-1,4- $\beta$-xylanase [Treponema azotonutricium] (WP_015711732.1) & 69.70 & \\
\hline$P W-x y / 32$ & 502 & 1,4- $\beta$-xylanase [Bacteroidetes bacterium GWE2_42_39] (OFY01282.1) & 63.91 & \\
\hline$P W-x y / 33$ & 583 & Endo-1,4- $\beta$-xylanase [Geitlerinema sp. PCC 9228] (WP_084639516.1) & 50.00 & \\
\hline$P W-x y / 34$ & 778 & Endo-1,4- $\beta$-xylanase [Marinilabilia salmonicolor] (WP_010663012.1) & 93.00 & \\
\hline$P W-x y / 35$ & 647 & Endo-1,4- $\beta$-xylanase [Hymenobactergummosus] (WP_126694067.1) & 44.70 & \\
\hline$P W-x y / 36$ & 711 & Endo-1,4- $\beta$-xylanase, GH35 family [Bacteroidales bacterium 6E] (GAP68157.1) & 69.05 & \\
\hline$P W-x y / 37$ & 723 & Endo-1,4- $\beta$-xylanase B [uncultured Bacteroides sp.] (SCJ93802.1) & 71.01 & $\checkmark$ \\
\hline$P W-x y / 38$ & 724 & Endo-1,4- $\beta$-xylanase [Ignavibacteriae bacterium] (RPI05742.1) & 50.14 & $\checkmark$ \\
\hline$P W-x y 139$ & 746 & Endo-1,4- $\beta$-xylanase [Moorea producens] (WP_083305227.1) & 51.95 & $\checkmark$ \\
\hline$P W-x y / 40$ & 746 & TPA: 1,4- $\beta$-xylanase [Cyanobacteria bacterium] (UBA11371] (HAZ45611.1) & 57.59 & \\
\hline
\end{tabular}

a $A$ is the length of the amino acid;

b If the last column is labeled

$\checkmark$, the expressed xylanase gene has xylanase activity

was defined as the amount of xylose released $/ \mathrm{min} / \mathrm{mg}$ enzyme. All data in the current study are presented as the means of triplicate experiments.
The optimum $\mathrm{pH}$ of xylanases was determined in buffers with different $\mathrm{pH}$ values. The sodium citratephosphate buffer was used from $\mathrm{pH} 4.5-6$, Tris- $\mathrm{HCl}$ buffer was applied from $\mathrm{pH} 6-9$, and glycine- $\mathrm{NaOH}$ buffer was used from $\mathrm{pH}$ 9-10. In order to determine 
the optimal $\mathrm{pH}$ and temperature for each enzyme, xylanase reactions were carried out at $50{ }^{\circ} \mathrm{C}$ and $\mathrm{pH}=7$, respectively. The highest xylanase activity detected in these experiments was defined as $100 \%$.

\section{Analyses of kinetic parameters and xylanase characterization}

The kinetic parameters of $\mathrm{K}_{\mathrm{m}}$ and $\mathrm{V}_{\max }$ were determined. The reaction was carried out for $3 \mathrm{~min}$ at the optimum temperature and $\mathrm{pH}$ determined for each xylanase. Values of $\mathrm{V}_{\max }$ and $\mathrm{K}_{\mathrm{m}}$ were calculated based on the data obtained. The Prosite protein database (https://prosi te.expasy.org/) was used to predict the structural domains and active sites of PW-xyl9 and PW-xyl37. The structural domains and signal peptides of proteins were predicted using the SignalP-5.0 server (Almagro Armenteros et al. 2019). Homologous modeling was conducted for the amino acid sequences of PW-xyl9 and PW-xyl37 with the SWISS-MODEL (Arnold et al. 2006). The quality of structural models was evaluated through the SAVES V5.0 server, and results were visualized by the PyMol molecular visualization system.

\section{Results}

\section{Expression and analysis of the $\mathbf{4 0}$ xylanase genes}

Using the primers designed with previous metagenomic data, 40 xylanase genes were cloned. These 40 xylanase genes were assigned to the GH10 family of glycoside hydrolases. These genes showed 27.16-98.67\% identity with genes in the GenBank database. Among them, the PW-Xyl9 gene had $89.3 \%$ identity with an endo-1,4- $\beta$-xylanase gene from Bacteroidales, while the $P W-X y l 28$ gene showed $27.16 \%$ identity with an endo1,4- $\beta$-xylanase of Cyanothece sp. PCC 7822. All the 40 cloned xylanase genes were different from xylanases with high activities in the BRENDA database (https://www. brenda-enzymes.org/) (Fig. 1). Fourteen of all 40 xylanase genes expressed in $E$. coli presented xylanase activity (Fig. 1 and Table 1).

\section{Expression of $P W$-xyl9 and $P W$-xyl37}

Among the 14 active xylanases, 11 crude xylanases had high xylanase activities (Additional file 1: Figure S1 and Table 1). The crude enzymes of PW-xyl9 and PWxyl37 showed higher xylanase activities compared with the remaining 12 active xylanases. Therefore, PW-xyl9 and PW-xyl37 were selected to determine their xylanase properties. These two proteins were subsequently expressed in E. coli and successfully purified (Additional file 1: Figure S2). Their molecular weights were determined as about 43 and $82 \mathrm{kDa}$, respectively, which were consistent with the predicted molecular weight based on the two corresponding genes (Table 1). According to our prediction, the active sites of PW-xyl9 are GLU162 and GLU267, whereas the active sites of PW-xyl37 are GLU 166 and GLU282, respectively (Additional file 1: Figure S3). Moreover, both PW-xyl9 and PW-xyl37 have signal peptides, indicating that these two xylanases may be extracellular xylanases which could be secreted and function outside of cells in the natural environment (Ohta et al. 2011).

\section{Enzymatic characteristics of PW-xyl9 and PW-xyl37}

The optimal $\mathrm{pH}$ and temperature of $\mathrm{PW}$-xyl9 were determined as pH 7 and $60{ }^{\circ} \mathrm{C}$, respectively; while the optimal $\mathrm{pH}$ and temperature of $\mathrm{PW}$-xyl37 were $\mathrm{pH} 7$ and $55{ }^{\circ} \mathrm{C}$, respectively (Fig. 2). It showed that the xylanase activity of PW-xyl9 can keep $>80 \%$ of its highest value from $\mathrm{pH}$ 6.5 to $\mathrm{pH} 8.0$, and keep $>50 \%$ of its highest value from 40 to $70{ }^{\circ} \mathrm{C}$. With respect to PW-xyl37, its xylanase activity could maintain $>80 \%$ of its highest value $\mathrm{pH} 6.5$ to $\mathrm{pH}$ 7.5 , whereas its xylanase activity could maintain $>50 \%$ of its highest value from 40 to $70{ }^{\circ} \mathrm{C}$.

Considering the optimal condition of beechwood as substrate, the specific xylanase activities of PW-xyl9 and $\mathrm{PW}$-xyl37 were $438.4 \mathrm{U} / \mathrm{mg}$ protein and $198.1 \mathrm{U} / \mathrm{mg}$ protein, respectively. With regards to enzymatic kinetics, PW-xyl9 had a $K_{\mathrm{m}}$ value of $5.95 \mathrm{~g} / \mathrm{L}, k_{\text {cat }}$ of $59.3 \mathrm{~S}^{-1}$, Vmax was $0.11 \mu \mathrm{M} / \mathrm{min}$, and catalytic efficiency $\left(\mathrm{Kcat} / \mathrm{K}_{\mathrm{M}}\right)$ of 9.97 (Additional file 1: Figure S4a and Table 2). The relevant values for PW-xyl37 were $K_{\mathrm{m}}=4.65 \mathrm{~g} / \mathrm{L}, \dot{k}_{\text {cat }}=36.1$ $\mathrm{S}^{-1}, \mathrm{~V}_{\max }=0.125 \mu \mathrm{M} / \mathrm{min}$, and $\mathrm{K}_{\mathrm{cat}} / \mathrm{K}_{\mathrm{M}}=7.76$, respectively (Additional file 1: Figure S4b and Table 2).

\section{Bioinformatics analysis of PW-xyl9 and PW-xyl37}

The SWISS-MODEL method was used to predict the quaternary structures of PW-xyl9 and PW-xyl37. The identity of amino acid sequence between PW-xyl9 and the xylanase (PDB: 1uqy) of Cellvibrio mixtus was $43 \%$ (Pell et al. 2004). This xylanase (PDB: 1uqy) was selected as template to construct the $3 \mathrm{D}$ structure model of PWxyl9. The expected accuracy of the model for PW-xyl9 was $G M Q E=0.73$, with a QMEAN value of -0.45 . The identity of amino acid sequence between PW-xyl37 and the xylanase (PDB: 5AY7) derived from goat rumen microbiota was $51 \%$, and this structure was selected as template to construct a 3D structure model of PW-xyl37. The GMQE and QMEAN values of PW-xyl37 were determined as 0.38 and -1.39 , respectively (Additional file 1 : Figure S5). These data indicate that the two predicted models are a good match with their template proteins (Benkert et al. 2009).

The quality of the built structure models was confirmed using the SAVES V5.0 server. The VERIFY value, ERRAT value, and the value of residues in most favored regions of PW-xyl9 were shown as 91.01,>95.2096, and 92.5\%, 


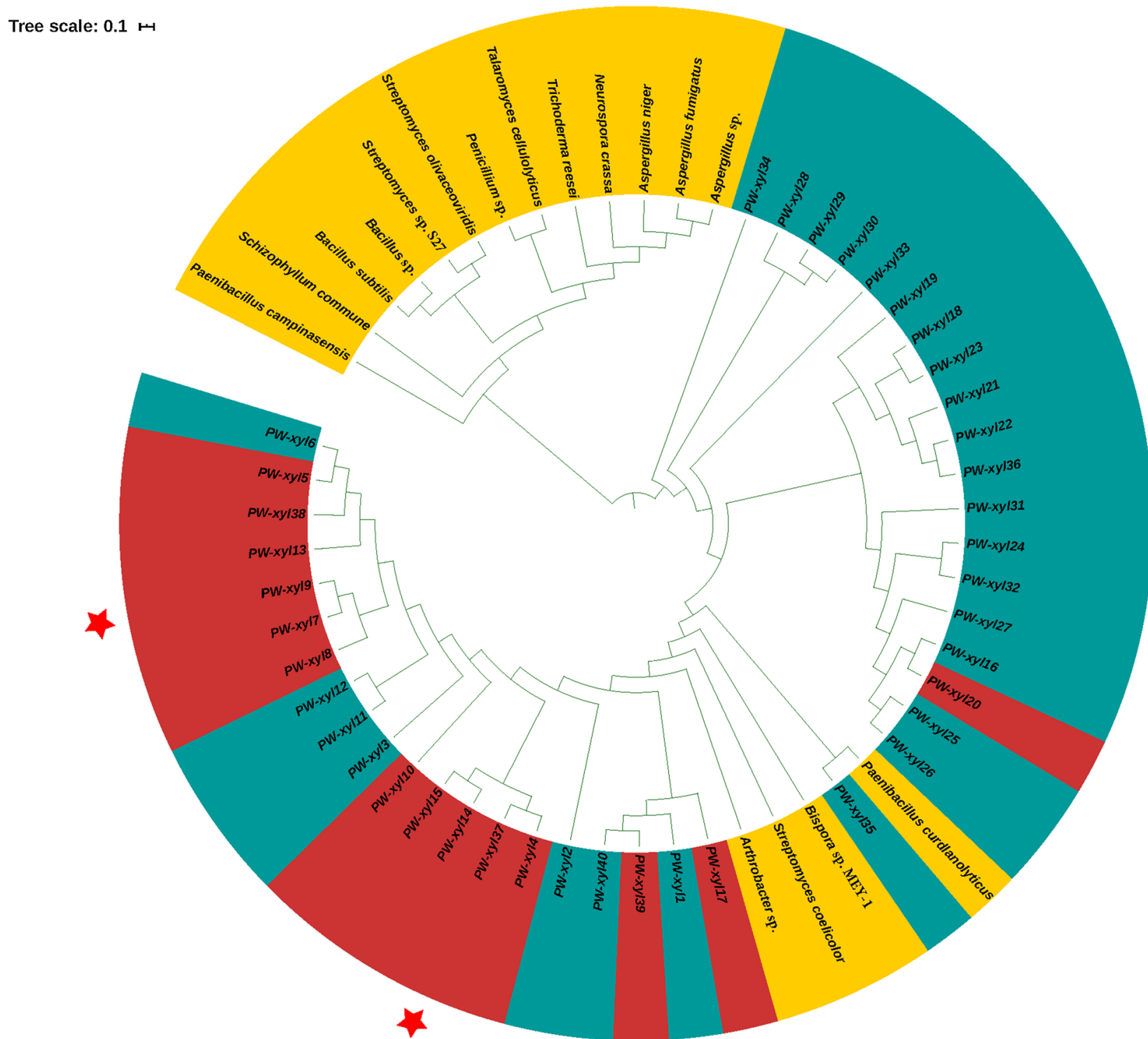

Fig. 1 The phylogenetic tree of the 40 verified xylanase genes and some xylanase genes downloaded from available database based on amino acid identity analyses with MEGA. The genes labeled yellow are xylanases with high activity retrieved from the enzyme repository of the ExPaSy database accessed at https://enzyme.expasy.org/. The microbial gene sources and their accession numbers are: Aspergillus niger XP_001388522.1, Bispora sp. MEY-1 ACS96449.1, Penicillium sp. ACY70400.1, Schizophyllum commune P35809.1, Talaromyces cellulolyticus BAO51921.1, Trichoderma reesei ACB38137.1, Aspergillus sp. Q4WG11.1, Neurospora crassa Q7SDQ1, Streptomyces coelicolor NP_733679.1, Bacillus subtilis P18429, Streptomyces sp. S27 ACF57948.1, Paenibacillus campinasensis Q216W5, Paenibacillus curdlanolyticus BAK22544.1, Bacillus sp. ACR47980.1, Arthrobacter sp. AGC01501.1, Streptomyces olivaceoviridis AHK22787.1. The 40 gene sequences with blue and red markings were expressed in E. coli; the ones marked red were expressed with xylanase activity, whereas the ones marked blue were expressed without xylanase activity. The two proteins labeled with two red star pentagons were selected to determine their xylanase properties after purification

respectively (Additional file 1: Figure S5). Meanwhile, the VERIFY value, ERRAT value, and value of residues in most favored regions of PW-xyl37 was 92.56,>96.5839, and 90.1, respectively (Additional file 1: Figure S5). Since a VERIFY value of $>80 \%$, an ERRAT value of $>85 \%$, and value of residues in most favored regions of $>90 \%$ are indicators of a good quality of a predicted model, the structural models predicted herein are good representatives of the real structures of PW-xyl9 and PW-xyl37.

The predicted 3D models of PW-xyl9 and PWxyl37 demonstrate that they harbor a classic $(\beta / \alpha)_{8^{-}}$ barrel fold (Fig. 3), which is present in about $10 \%$ of known enzyme structures and is the characteristics of 

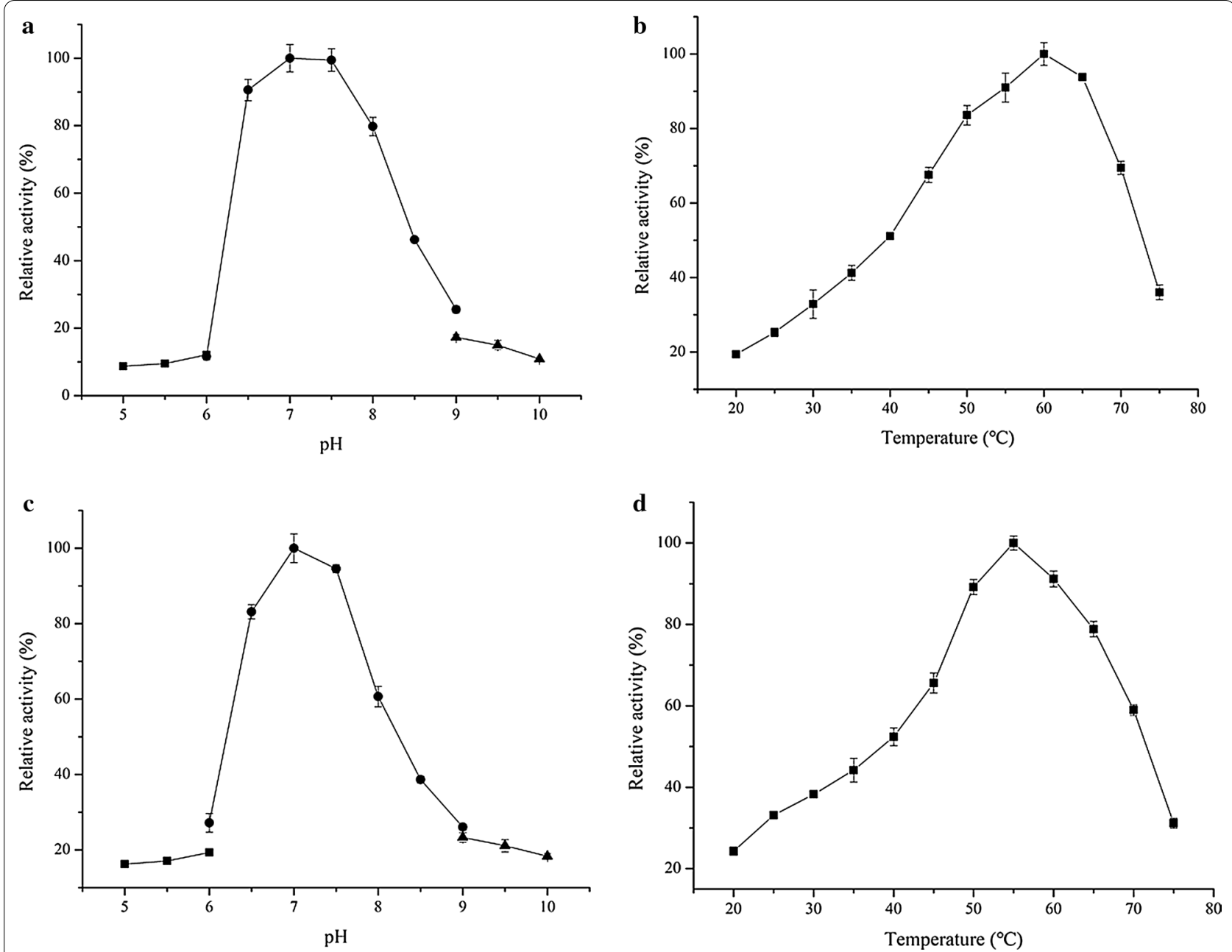

Fig. 2 Enzymatic characteristics of PW-xyl9 and PW-xyl37. a Optimal pH value for PW-xyl9. b Optimal temperature value for PW-xyl9. c Optimal pH value for PW-xyl37. d Optimal temperature value for PW-xyl37. The $\mathrm{pH}$ range was 5-10, and the buffer systems used were: citrate-phosphate (

for the $\mathrm{pH}$ 5-6 range, Tris- $\mathrm{HCl}(\boldsymbol{\bullet})$ for the $\mathrm{pH}$ 6-9 range, glycine- $\mathrm{NaOH}(\mathbf{\Delta})$ for the $\mathrm{pH}$ 9-10 range. The value represents the mean value of triplicate experiments, and the error bar indicates standard deviation

Table 2 Enzyme activity parameters of PW-Xyl9 and PW-Xyl37

\begin{tabular}{lllll}
\hline Names & $\begin{array}{l}\mathrm{K}_{\mathrm{m}}(\mathbf{m g} / \\
\mathbf{m l})\end{array}$ & $\begin{array}{l}\mathrm{V}_{\max }(\boldsymbol{\mu M} / \\
\mathbf{m i n})\end{array}$ & $\begin{array}{l}\mathrm{K}_{\mathrm{cat}} \\
\left(\mathbf{s e c}^{-\mathbf{1}}\right)\end{array}$ & $\begin{array}{l}\mathrm{K}_{\mathrm{cat}} / \mathrm{K}_{\mathrm{m}} \\
\left(\mathbf{m L}^{*} \mathbf{m g}^{-\mathbf{1}} \mathbf{s e c}^{-\mathbf{1}}\right)\end{array}$ \\
\hline PW-Xy19 & 5.95 & 0.110 & 59.3 & 9.97 \\
PW- & 4.65 & 0.125 & 36.1 & 7.76 \\
Xy|37 & & & & \\
\hline
\end{tabular}

xylanases of the GH10 family, further evidencing that PW-xyl9 and PW-xyl37 are indeed GH family xylanases (Sterner and Hocker 2005). Based on analysis by APBS software, PW-xyl9 and PW-xyl37 are electronegative (Fig. 3).

\section{Discussion}

With the improvement of omics technologies and microbiome analysis, many efficient lignocellulose degradation systems have been investigated (Liu et al. 2019; Stewart et al. 2018; Wei et al. 2015). Diverse lignocellulase genes have been recovered from natural lignocellulose-degrading microbiota, including the termite hindgut and the cow rumen (Al-Darkazali et al. 2017; Joshi et al. 2020; Verma et al. 2013). About one million GH gene modules have been identified and included in the CAZy database (Lombard et al. 2014). Moreover, large amounts of novel lignocellulase genes from a particular PPWT microbiota were identified in our previous study (Liang et al. 2021). As xylan is one of the most abundant components of biomass in nature, it is 


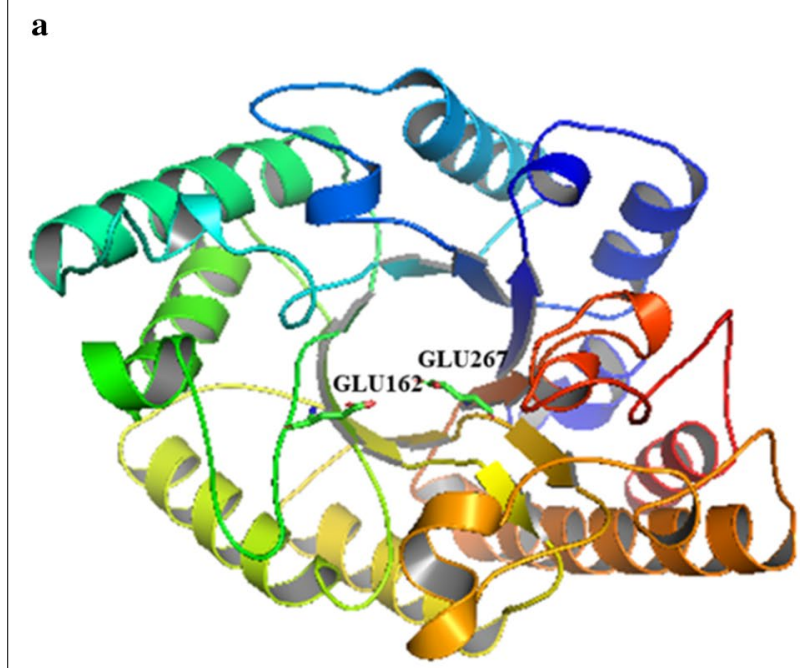

b
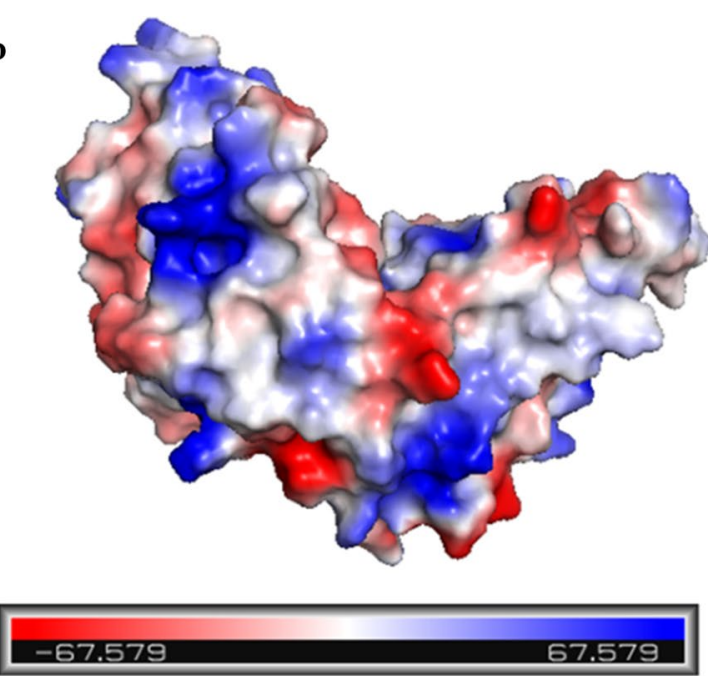

c

d
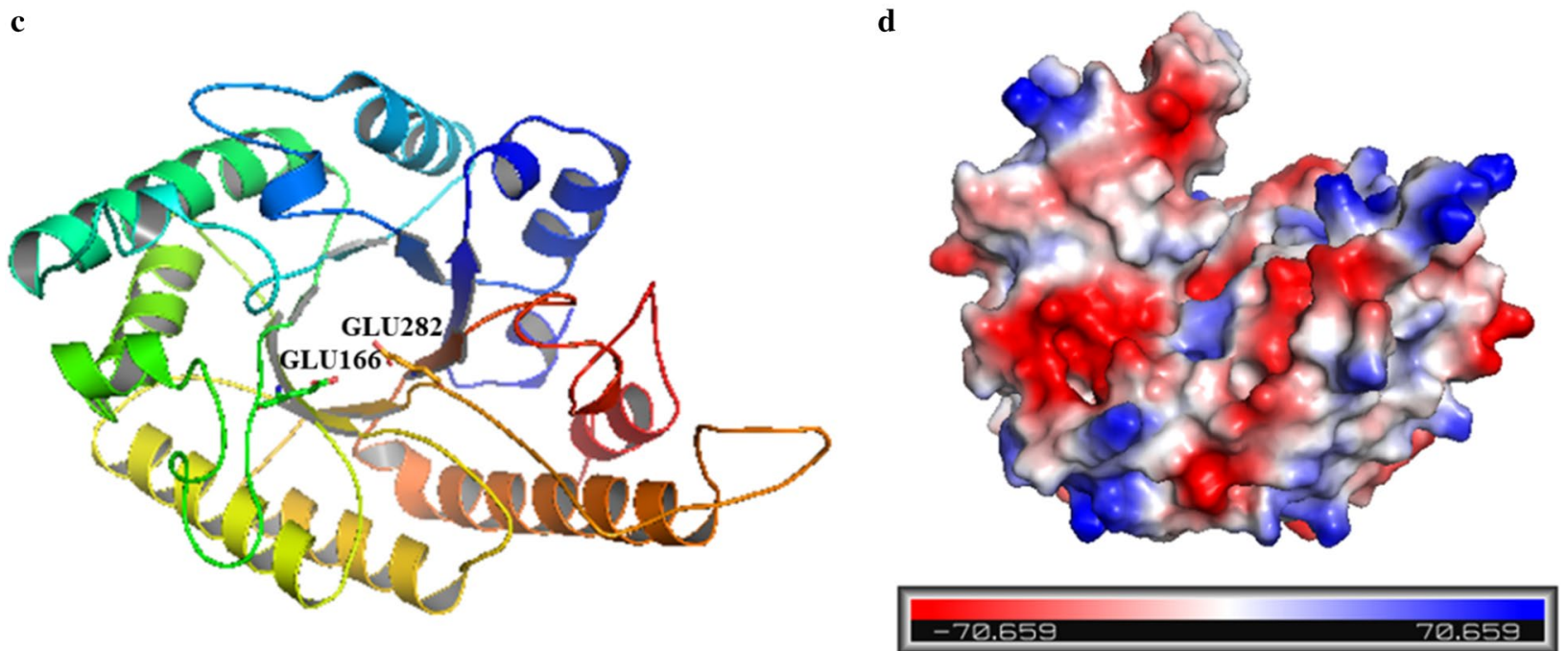

Fig. 3 3D model and electrostatic properties of PW-Xyl9 and PW-Xyl37. a 3D model of PW-Xy|9. GLU162 and GLU267 are the active sites of PW-Xyl9. b Electrostatic properties of PW-Xyl9. c 3D model of PW-Xyl37. GLU166 and GLU282 are the active sites of PW-Xyl37. d Electrostatic properties of PW-Xyl37. Enzyme electrostatic properties were predicted with PyMOL software. The red surface indicates that the relevant area has strong positive electrostatic properties, while the blue surface indicates the area has strong negative electrostatic properties

of great importance to screen novel efficient xylanases from natural microbiota (Madeira et al. 2017). Compared with a lab-scale biogas digester, a diverse array of xylanase genes from the GH10 family and a number of xylanase genes from the GH11 family were identified in the abovementioned PPWT microbiota, showing that GH10 family xylanases in such microbiota might perform well in xylan degradation (Liang et al. 2021). Two xylanases with high activities were characterized in the present study, suggesting that GH10 family xylanases might play essential roles in xylan degradation by PPWT microbiota (Liang et al. 2021).
The optimal $\mathrm{pH}$ of the two characterized xylanases was $\mathrm{pH}$ 7. Considering that the functional $\mathrm{pH}$ for the studied microbiota was in the range of $\mathrm{pH} 7-9$ (Fig. 2), xylanases and their hosts occurring in the microbiota might show adaptation to the $\mathrm{pH}$ environment of PPWT. Optimal temperatures for these two characterized xylanases were 55 and $60{ }^{\circ} \mathrm{C}$, respectively, however, they exhibited high activities from 40 to $75{ }^{\circ} \mathrm{C}$. The running temperature of the studied PPWT microbiota was $38^{\circ} \mathrm{C}$ (Liang et al. 2021), suggesting that these xylanases show robustness. In fact, the types of lignocellulase identified in mesophilic biogas digesters and the 
termite hindgut exhibited high activities at temperatures above $40{ }^{\circ} \mathrm{C}$ (Qian et al. 2015; Yan et al. 2013), which is consistent with the results of our study. The two xylanases characterized herein have signal peptides (Roslan et al. 2020), indicating that they might be secreted and functional extracellularly in PPWT bioreactors. The xylanase activities in the PPWT bioreactors were low, which might be explained by the suboptimal running temperature and complex environment in these bioreactors (Liang et al. 2021). Furthermore, a complex mixture of substrates was present in the pulp and paper wastewater, and the xylan content might not be high, thus even low xylanase activity in the bioreactors was sufficient to degrade all the xylan in the wastewater.

Xylanases are mainly used in the pulp bleaching, baking, and food industries (Walia et al. 2017). Some of these technologies require xylanases to be active at higher temperatures and alkaline environments (Mhiri et al. 2020). The two xylanases characterized in this study functioned at conditions of a wide range of $\mathrm{pH}$ and higher temperature, evidencing their potential application in the pulp bleaching and other industries. Commercial xylanases are required to be thermostable and robust to recalcitrant conditions. Analyses of surface electrostatic potential indicate that PW-xyl9 and PW-xyl37 are electronegative, suggesting that these two xylanases might have good thermal stability (Zhou et al. 2019). Compared with the xylanases deposited in the BRENDA database, the activities of the two characterized xylanases are not high, and further engineering of these two enzymes for higher xylanase activities and higher thermostability are necessary. Our enzyme structure models identified the active sites of the two characterized xylanases, which might be useful for the future engineering of xylanases with enhanced activity and thermal stability. The directed evolution and rational design guided strategies can be used to improve the characters of these two enzymes (Xing et al. 2021).

Environmental biotechnology has recovered large amounts of functional genes from natural microbiota, however, most genes have not been characterized to date (Ariaeenejad et al. 2019; Stewart et al. 2018). Some of the xylanase genes identified from PPWT microbiota in this paper showed $>60 \%$ identities with known genes in the GenBank database (Table 1), while the function of these genes was not verified against GenBank. Herein, 14 genes with xylanase activities were identified by expressing a total of 40 xylanase genes in E. coli, showing that the heterologous expression system of xylanase genes in $E$. coli cannot express all recovered genes. Therefore, the future development of novel efficient microbial chassis systems for functional environmental gene expression might improve the understanding of functional genes and their respective catalytic mechanisms in natural microbiota (de Paula et al. 2019; Kim et al. 2020). Nowadays, the progressive engineering of expression systems in microbial hosts, such as Saccharomyces cerevisiae, might lead to an efficient microbial cell factory for lignocellulose degradation (Tang et al. 2017).

In the present study, we cloned and expressed 40 xylanase genes, recovered from a particular PPWT microbiota, in E. coli. Fourteen of these genes showed xylanase activity, and two with high xylanase activity were characterized. Moreover, they function under a wide range of $\mathrm{pH}$ and temperature conditions, indicating they have potential application in industry. Bioinformatics analyses were used to give an insight into the structure of these two characterized xylanases, which might be applicable for the improvement of thermostability and other properties of industrial xylanases through protein engineering in the future.

\section{Supplementary information}

The online version contains supplementary material available at https://doi. org/10.1186/s13568-020-01178-1.

Additional file 1. Additional Table and Figures.

\section{Acknowledgements}

This work was funded by the National Natural Science Foundation of China (No. 31800079 for Yongjun Wei), Henan Shangxing Environmental protection Technology Co., Ltd, Henan Muyi Animal Pharmaceutical Co., Ltd, Kaifeng Muyi Huamiao Biological Technology Co., Ltd, and Henan Junhe Environmental Technology Co., Ltd. We would like to thank TopEdit (www.topeditsci.com) for English language editing of this manuscript.

\section{Authors' contributions}

YW, LT and YL conceived this study. JW and JL done the experiment. JW and $Y W$ wrote the manuscript. JL, LT and $Y L$ revised the manuscript. All authors contributed to the article. All authors read and approved the final manuscipt.

Availability of data and materials

The accession numbers of the 40 xylanase genes are MW124392-MW124431 in GenBank database.

\section{Ethics approval and consent to participate}

This article does not contain any studies with human participants or animals performed by any of the authors.

\section{Competing interests}

The authors declare that they have no conflict of interest.

\section{Author details}

${ }^{1}$ Key Laboratory of Advanced Drug Preparation Technologies, Ministry of Education, School of Pharmaceutical Sciences, Zhengzhou University, Zhengzhou, People's Republic of China. ${ }^{2}$ College of Public Health, Zhengzhou University, Zhengzhou, Henan 450001, People's Republic of China. ${ }^{3}$ Department of Food Science and Engineering, Jinan University, Guangzhou 510632, People's

Republic of China.

Received: 29 December 2020 Accepted: 31 December 2020

Published online: 19 January 2021 


\section{References}

Al-Darkazali H, Meevootisom V, Isarangkul D, Wiyakrutta S (2017) Gene expression and molecular characterization of a xylanase from chicken cecum metagenome. Int J Microbiol 2017:4018398

Almagro Armenteros JJ, Tsirigos KD, Sønderby CK, Petersen TN, Winther O, Brunak S, von Heijne G, Nielsen H (2019) SignalP 5.0 improves signal peptide predictions using deep neural networks. Nat Biotechnol 37(4):420-423

Ariaeenejad S, Maleki M, Hosseini E, Kavousi K, Moosavi-Movahedi AA, Salekdeh GH (2019) Mining of camel rumen metagenome to identify novel alkali-thermostable xylanase capable of enhancing the recalcitrant lignocellulosic biomass conversion. Bioresour Technol 281:343-350

Arnold K, Bordoli L, Kopp J, Schwede T (2006) The SWISS-MODEL workspace: a web-based environment for protein structure homology modelling. Bioinformatics 22(2):195-201

Benkert P, Kunzli M, Schwede T (2009) QMEAN server for protein model quality estimation. Nucleic Acids Res 37:W510-W514

Bhardwaj A, Mahanta P, Ramakumar S, Ghosh A, Leelavathi S, Reddy VS (2012) Emerging role of $\mathrm{N}$ - and $\mathrm{C}$-terminal interactions in stabilizing $(\beta / a)_{8}$ fold with special emphasis on Family 10 xylanases. Comput Struct Biotechnol J 2:e201209014

Collins T, Gerday C, Feller G (2005) Xylanases, xylanase families and extremophilic xylanases. FEMS Microbiol Rev 29(1):3-23

de Paula RG, Antoniêto ACC, Ribeiro LFC, Srivastava N, O'Donovan A, Mishra PK, Gupta VK, Silva RN (2019) Engineered microbial host selection for value-added bioproducts from lignocellulose. Biotechnol Adv 37(6):107347

Ghadikolaei KK, Sangachini ED, Vahdatirad V, Noghabi KA, Zahiri HS (2019) An extreme halophilic xylanase from camel rumen metagenome with elevated catalytic activity in high salt concentrations. AMB Express 9(1):86

Gharechahi J, Salekdeh GH (2018) A metagenomic analysis of the camel rumen's microbiome identifies the major microbes responsible for lignocellulose degradation and fermentation. Biotechnol Biofuels 11(1):216

Han Q, Liu N, Robinson H, Cao L, Qian C, Wang Q, Xie L, Ding H, Wang Q, Huang Y, Li J, Zhou Z (2013) Biochemical characterization and crystal structure of a GH10 xylanase from termite gut bacteria reveal a novel structural feature and significance of its bacterial lg-like domain. Biotechnol Bioeng 110(12):3093-3103

Houfani AA, Anders N, Spiess AC, Baldrian P, Benallaoua S (2020) Insights from enzymatic degradation of cellulose and hemicellulose to fermentable sugars - a review. Biomass Bioenergy 134:105481

Hu R, Lin L, Liu T, Ouyang P, He B, Liu S (2008) Reducing sugar content in hemicellulose hydrolysate by DNS method: a revisit. J Biobased Mater Bioenergy 2(2):156-161

Jeong YS, Na HB, Kim SK, Kim YH, Kwon EJ, Kim J, Yun HD, Lee JK, Kim H (2012) Characterization of xyn 10J, a novel family 10 xylanase from a compost metagenomic library. Appl Biochem Biotechnol 166(5):1328-1339

Jia X, Han Y (2019) The extracellular endo- $\beta-1,4$-xylanase with multidomain from the extreme thermophile Caldicellulosiruptor lactoaceticus is specific for insoluble xylan degradation. Biotechnol Biofuels 12(1):143

Joshi N, Sharma M, Singh SP (2020) Characterization of a novel xylanase from an extreme temperature hot spring metagenome for xylooligosaccharide production. Appl Microbiol Biotechnol 104(11):4889-4901

Juturu V, Wu JC (2012) Microbial xylanases: engineering, production and industrial applications. Biotechnol Adv 30(6):1219-1227

Kim HB, Lee KT, Kim MJ, Lee JS, Kim KS (2018) Identification and characterization of a novel KG42 xylanase (GH10 family) isolated from the black goat rumen-derived metagenomic library. Carbohydr Res 469:1-9

Kim K, Choe D, Lee DH, Cho BK (2020) Engineering biology to construct microbial chassis for the production of difficult-to-express proteins. Int $J$ Mol Sci 21(3):990

Kumar S, Stecher G, Tamura K (2016) MEGA7: Molecular Evolutionary Genetics Analysis version 7.0 for bigger datasets. Mol Biol Evol 33(7):1870-1874

Kumar V, Dangi AK, Shukla P (2018) Engineering thermostable microbial xylanases toward its industrial applications. Mol Biotechnol 60(3):226-235

Letunic I, Bork P (2019) Interactive Tree Of Life (iTOL) v4: recent updates and new developments. Nucleic Acids Res 47(W1):W256-W259

Liang J, Mai W, Wang J, Li X, Su M, Du J, Wu Y, Dai J, Tang Q, Gao J, Liu Y, Tang J, Wei $Y$ (2021) Performance and microbial communities of a novel integrated industrial-scale pulp and paper wastewater treatment plant. J Clean Prod 278:123896
Liu N, Yan X, Zhang M, Xie L, Wang Q, Huang Y, Zhou X, Wang S, Zhou Z (2011) Microbiome of fungus-growing termites: a new reservoir for lignocellulase genes. Appl Environ Microbiol 77(1):48-56

Liu N, Li H, Chevrette MG, Zhang L, Cao L, Zhou H, Zhou X, Zhou Z, Pope PB, Currie CR, Huang Y, Wang Q (2019) Functional metagenomics reveals abundant polysaccharide-degrading gene clusters and cellobiose utilization pathways within gut microbiota of a wood-feeding higher termite. ISME J 13(1):104-117

Loaces I, Bottini G, Moyna G, Fabiano E, Martínez A, Noya F (2016) EndoG: a novel multifunctional halotolerant glucanase and xylanase isolated from cow rumen. J Mol Catal B Enzym 126:1-9

Lombard V, Golaconda Ramulu H, Drula E, Coutinho PM, Henrissat B (2014) The carbohydrate-active enzymes database (CAZy) in 2013. Nucleic Acids Res 42(Database issue):D490-D495

Madeira JV, Contesini FJ, Calzado F, Rubio MV, Zubieta MP, Lopes DB, de Melo RR (2017) Chapter 18-Agro-Industrial Residues and Microbial Enzymes: an overview on the eco-friendly bioconversion into high value-added products. In: Brahmachari G (ed) Biotechnology of microbial enzymes. Academic Press, Cambridge, pp 475-511

Mhiri S, Bouanane-Darenfed A, Jemli S, Neifar S, Ameri R, Mezghani M, Bouacem K, Jaouadi B, Bejar S (2020) A thermophilic and thermostable xylanase from Caldicoprobacter algeriensis: recombinant expression, characterization and application in paper biobleaching. Int J Biol Macromol 164:808-817

Ohta K, Tanaka H, Yamakawa D, Hamasuna H, Fujimoto H (2011) Signal peptide of Aureobasidium pullulans xylanase: use for extracellular production of a fungal xylanase by Escherichia coli. J Ind Microbiol Biotechnol 38(8):967-973

Pell G, Taylor EJ, Gloster TM, Turkenburg JP, Fontes CM, Ferreira LM, Nagy T, Clark SJ, Davies GJ, Gilbert HJ (2004) The mechanisms by which family 10 glycoside hydrolases bind decorated substrates. J Biol Chem 279(10):9597-9605

Qian C, Liu N, Yan X, Wang Q, Zhou Z, Wang Q (2015) Engineering a high-performance, metagenomic-derived novel xylanase with improved soluble protein yield and thermostability. Enzyme Microb Technol 70:35-41

Roslan AM, Mustafa Kamil A, Chandran C, Song AA-L, Yusoff K, Abdul Rahim $R$ (2020) Secretion of recombinant xylanase in Lactococcus lactis using signal peptides Usp45 and Spk1. Biotechnol Lett 42(9):1727-1733

Sawatdeenarunat C, Surendra KC, Takara D, Oechsner H, Khanal SK (2015) Anaerobic digestion of lignocellulosic biomass: challenges and opportunities. Bioresour Technol 178:178-186

Scheller HV, Ulvskov P (2010) Hemicelluloses. Annu Rev Plant Biol 61:263-289

Shallom D, Shoham Y (2003) Microbial hemicellulases. Curr Opin Microbiol 6(3):219-228

Sterner R, Hocker B (2005) Catalytic versatility, stability, and evolution of the $(\beta / a)_{8}$-barrel enzyme fold. Chem Rev 105(11):4038-4055

Stewart RD, Auffret MD, Warr A, Wiser AH, Press MO, Langford KW, Liachko I, Snelling TJ, Dewhurst RJ, Walker AW, Roehe R, Watson M (2018) Assembly of 913 microbial genomes from metagenomic sequencing of the cow rumen. Nat Commun. https://doi.org/10.1038/s41467-018-03317-6

Tang H, Song M, He Y, Wang J, Wang S, Shen Y, Hou J, Bao X (2017) Engineering vesicle trafficking improves the extracellular activity and surface display efficiency of cellulases in Saccharomyces cerevisiae. Biotechnol Biofuels 10:53

Teixeira RS, da Silva AS, Ferreira-Leitao VS, da Silva Bon EP (2012) Amino acids interference on the quantification of reducing sugars by the 3,5-dinitrosalicylic acid assay mislead carbohydrase activity measurements. Carbohydr Res 363:33-37

Torres JM, Dela Cruz TE (2013) Production of xylanases by mangrove fungi from the Philippines and their application in enzymatic pretreatment of recycled paper pulps. World J Microbiol Biotechnol 29(4):645-655

Verma D, Kawarabayasi Y, Miyazaki K, Satyanarayana T (2013) Cloning, expression and characteristics of a novel alkalistable and thermostable xylanase encoding gene $(\mathrm{Mxyl})$ retrieved from compost-soil metagenome. PLoS ONE 8(1):e52459

Walia A, Guleria S, Mehta P, Chauhan A, Parkash J (2017a) Microbial xylanases and their industrial application in pulp and paper biobleaching: a review. Biotech 7(1):11

Wei Y, Zhou H, Zhang J, Zhang L, Geng A, Liu F, Zhao G, Wang S, Zhou Z, Yan X (2015) Insight into dominant cellulolytic bacteria from two biogas digesters and their glycoside hydrolase genes. PLoS ONE 10(6):e0129921 
Wirth R, Kádár G, Kakuk B, Maróti G, Bagi Z, Szilágyi Á, Rákhely G, Horváth J, Kovács KL (2018) The planktonic core microbiome and core functions in the cattle rumen by next generation sequencing. Front Microbiol. https:// doi.org/10.3389/fmicb.2018.02285

Wu H, loannou E, Henrissat B, Montanier CY, Bozonnet S, O'Donohue MJ, Dumon C (2020) Investigating the multi-modularity of a GH10 xylanase found in termite gut metagenome. Appl Environ Microbiol. https://doi. org/10.1128/AEM.01714-20

Xing BS, Cao S, Han Y, Wang XC, Wen J, Zhang K (2020) A comparative study of artificial cow and sheep rumen fermentation of corn straw and food waste: batch and continuous operation. Sci Total Environ 745:140731

Xing H, Zou G, Liu C, Chai S, Yan X, Li X, Liu R, Yang Y, Zhou Z (2021) Improving the thermostability of a GH11 xylanase by directed evolution and rational design guided by B-factor analysis. Enzyme Microb Technol 143:109720

Yan X, Geng A, Zhang J, Wei Y, Zhang L, Qian C, Wang Q, Wang S, Zhou Z (2013) Discovery of (hemi-) cellulase genes in a metagenomic library from a biogas digester using 454 pyrosequencing. Appl Microbiol Biotechnol 97(18):8173-8182

Zhang Y, An J, Yang G, Zhang X, Xie Y, Chen L, Feng Y (2016) Structure features of GH10 xylanase from Caldicellulosiruptor bescii: implication for its thermophilic adaption and substrate binding preference. Acta Biochim Biophys Sin 48(10):948-957

Zhou Y, Pérez B, Hao W, Lv J, Gao R, Guo Z (2019) The additive mutational effects from surface charge engineering: a compromise between enzyme activity, thermostability and ionic liquid tolerance. Biochem Eng J 148:195-204

\section{Publisher's Note}

Springer Nature remains neutral with regard to jurisdictional claims in published maps and institutional affiliations.

\section{Submit your manuscript to a SpringerOpen ${ }^{\circ}$ journal and benefit from:}

- Convenient online submission

- Rigorous peer review

- Open access: articles freely available online

- High visibility within the field

- Retaining the copyright to your article

Submit your next manuscript at $\boldsymbol{\nabla}$ springeropen.com 